\title{
Robotics and Design: an Interdisciplinary Crash Course
}

\author{
Andrea Bonarini, Member IEEE, Maximiliano Romero
}

\begin{abstract}
The authors designed and ran a crash course on emotional robotics involving students from both the Information Engineering School and the Design School of Politecnico di Milano. The course consisted of two intensive days of short introductory lessons and lab activity, done in interdisciplinary groups and supported by a well-equipped prototyping and modeling lab. People from very different backgrounds had to work efficiently together, going from problem setting through the demonstration of the physical implementation of an object able to show four different emotional states. Both teacher evaluation, and questionnaire-based feedback from the students, show that it was successful and useful to set up this type of intensive experience in which students share their abilities to achieve a common goal. Key aspects for the success of the course were the short time the students had to reach a well-defined, yet general, goal, the students' ability to find efficient ways of cooperating and sharing their competences, students' motivation to arrive at a working prototype, and the strong support from teachers and lab personnel.
\end{abstract}

Index Terms-Constructivism, design, interdisciplinary course, laboratory course, learning-by-doing, robotics

\section{INTRODUCTION}

In 2007, Bill Gates stated [1]: "I can envision a future in which robotic devices will become a nearly ubiquitous part of our day-to-day lives." Key to really bringing robots into every house is that they should be designed with the approach used to design most of the objects that are now in homes, by considering the user's needs and wishes (usercentred design [2]). This could be a major opportunity for new, skilled robot designers. Key to the successful diffusion of these devices is that their design adheres to design principles, and is carried out with a strong interaction between those working on the technical aspects (such as sensors, actuators, or programming) and those working on the design-related aspects (such as shape, usability, or interaction).

An interdisciplinary initiative to train these robot designers, was launched at the Politecnico di Milano, Italy, bringing together teachers and students from the Information Engineering School and the Design School, each bringing their own characteristic competences and approaches to design and work in this multidisciplinary area: engineers, trained in the technical aspects of robotics; and designers, who are trained to create and design new ideas according to core design principles, but who do not have a mastery of robotics' technical issues.

A. Bonarini is with the Department of Electronics and Information (DEI), Politecnico di Milano, Milan, Italy e-mail: andrea.bonarini@polimi.it.

M. Romero is with Industrial Design, Communication, Arts and Fashion Department (INDACO), Politecnico di Milano, Milan, Italy e-mail: maximiliano.romero@polimi.it
This paper reports the first experiment in this direction, a "crash course" held in February 2012, to see how to train robot designers with these skills. The tradition of the Design School at the Politecnico di Milano is to give an important role to the physical realization of models, and people working in robotics also need to see their creations in operation, so the course was based on the physical implementation of robots. Because the course was not included in any official curricular track, and offered the participating teachers or students (all volunteers) no reward other than the pleasure of the thing itself, it had to be a short course, requiring limited participant time.

The specific topic of the course, which had to appeal to both designers and engineers, was "Emotion in Robotics: How Can Robots Communicate Emotions?" This title should intrigue both engineers and designers: emotion is currently a buzzword in design, and robotics has strong connotations in the collective imagination, including that of designers; and the idea of giving emotion to a device is certainly appealing to engineers. The teaching staff was also interesting, including a cartoon designer, among others.

The pedagogical goals of the course, apart from the subjectmatter, were: the development of interdisciplinary teamwork capabilities, problem setting, and project management under tight constraints, and the development of Goldberg's seven "missing basics" [3] (asking questions, labelling technology and design challenges, modelling problems qualitatively, decomposing design problems, gathering data, visualizing solutions and generating ideas, and communicating solutions in written and oral form).

The next section describes the design of the course.

\section{Instruments AND METHODS}

The course was designed to have a strong practical part, to be carried out in interdisciplinary groups in the lab, following the Schools' traditional approach, and the learning-bydoing [4] and constructivist [5] principles.

\section{A. Recruitment}

An open call for participation was issued using posters in both Schools, direct invitations to selected candidates, and posting on social networks social networks: Facebook, Twitter, and student networks, all fed in part by the students themselves. The call was addressed to very motivated, volunteer students: no university credit or other reward was offered, other than participating in an exciting initiative. No specific knowledge was required, just an interest in this kind of interdisciplinary teamwork. The call was closed when the desired number of participants was reached: ten students from each School. 


\section{B. Physical Setting}

The crash course was held in the Models and Prototypes Laboratory of the Industrial Design, Communication, Arts and Fashion Department (INDACO) of the Politecnico di Milano. A $100 \mathrm{~m}^{2}$ room, Fig. 1, in the fully-equipped $1000 \mathrm{~m}^{2}$ laboratory was dedicated to this course, providing enough space for all the activities. Access to the equipment in the room and elsewhere in the Lab was in part mediated and supported by technical staff.

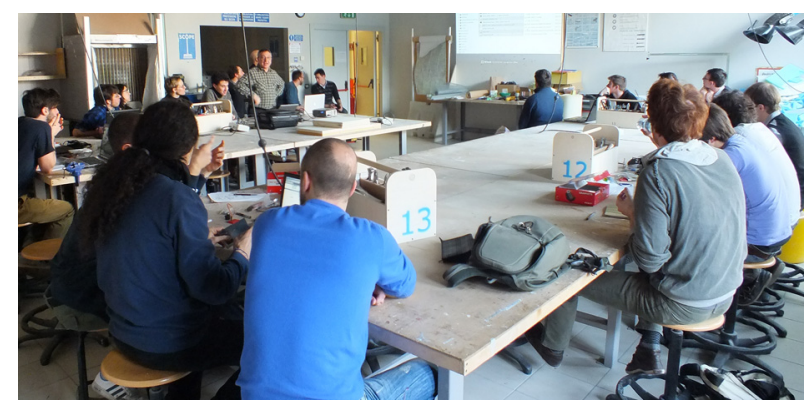

Fig. 1. The course room in the Models and Prototypes Laboratory

\section{Teaching Staff}

The staff was composed of a full professor of robotics from the Engineering school, a lecturer in industrial design from the Design school, an animation character expert, and three INDACO laboratory technicians (one from the Physical Computing Laboratory and two from the hosting lab). All the teachers gave lessons and were present during the two-day course, supporting the student groups.

\section{Students and Team Organization}

Twenty Bachelor's, Master's and Ph.D. students from eight different tracks of the two Schools were involved. These included:

- Ten students from the Design School: seven from Product Design, one from Communication Design, one from Design and Engineering, and one Ph.D. in Design.

- Ten students from the Information Engineering School: four from Computer Engineering (where intelligent robotics courses are held), three from Automation (where industrial robotics courses are held), two from Electronics Engineering, and one from Electrical Engineering.

Students were organized into five four-person groups, each including two designers and two engineers. Backgrounds and levels were evenly distributed, and acquaintances were separated, so as to have groups with disparate competences, whose members were unfamiliar to each other.

No leadership was defined a priori for the groups: they were left to self-organize under the tight resource and time constraints, according to the set pedagogical goals.

All the groups had to produce a prototype robot able to communicate four given emotions: pleasure, surprise, rage, and terror. Two teams had to produce something like a face (with eyes, mouth, and so on), two teams had to produce an
TABLE I

THE STUDENT DISTRIBUTION AMONG GROUPS

\begin{tabular}{|c|c|c|c|}
\hline Team & Goal & School & Course program \\
\hline 1 & Body & $\begin{array}{c}\text { Design } \\
\text { Design } \\
\text { Engineering } \\
\text { Engineering }\end{array}$ & $\begin{array}{c}\text { Product Design } \\
\text { Communication Design } \\
\text { Automation Engineering } \\
\text { Computer Engineering }\end{array}$ \\
\hline 2 & Face & $\begin{array}{c}\text { Design } \\
\text { Design } \\
\text { Engineering } \\
\text { Engineering }\end{array}$ & $\begin{array}{c}\text { Product Design } \\
\text { Product Design } \\
\text { Automation Engineering } \\
\text { Computer Engineering }\end{array}$ \\
\hline 3 & Body & $\begin{array}{c}\text { Design } \\
\text { Design } \\
\text { Engineering } \\
\text { Engineering }\end{array}$ & $\begin{array}{c}\text { Product Design } \\
\text { Communication Design } \\
\text { Electrical Engineering } \\
\text { Computer Engineering }\end{array}$ \\
\hline 4 & Face & $\begin{array}{c}\text { Design } \\
\text { Design } \\
\text { Engineering } \\
\text { Engineering }\end{array}$ & $\begin{array}{l}\text { Design \& Engineering } \\
\text { Product Design } \\
\text { Automation Engineering } \\
\text { Computer Engineering }\end{array}$ \\
\hline 5 & Free & $\begin{array}{c}\text { Design } \\
\text { Design } \\
\text { Engineering } \\
\text { Engineering }\end{array}$ & $\begin{array}{c}\text { Product Design } \\
\text { Ph.D. in Design } \\
\text { Electronics Engineering } \\
\text { Computer Engineering }\end{array}$ \\
\hline
\end{tabular}

object that was not a face (a cube was independently selected by both), and the last team was free to decide the shape of their robot. The group organization is shown in Table I.

\section{E. Course Organization}

The course was divided in two main sections: 15-minute theory lessons introducing topics related to the proposed activity; and practical laboratory work, with continuous support and stimulation from the teaching staff.

The topics of the lessons, taught to all the students, were:

- Physical Computing: basics of the Arduino open source HW/SW platform [6] and how to program it, what can be connected to the Arduino, synchronization of actuators.

- Emotion and robotics: how robots can show emotions, uncanny valley [7], geminoids [8], robotic animals, puppets, human mimics and emotion, static facial expressions vs. movements and dynamics.

- Shape and modeling: how to model a shape with different materials, mechanical building (basics about movement generation, the use of servo motors, leverage and motion transmission), safety norms.

- Emotion rendering: techniques to design emotion in cartoons [9], motion decomposition, both static and dynamic key cues for emotions.

The aims of these lessons were to provide a common, basic background for all the students, to be developed autonomously in the following lab activities. Section III will comment on how well this was achieved.

Checkpoints were defined every three hours of activity. These checkpoints were for the concept, the mechanical design, the mechanical implementation, programming movements, and the final show.

A meal was shared every day, with everyone gathering to eat pizza around a large, common table, to foster group interaction. 


\section{F. Materials}

Each group received a similar materials kit, containing electronic components (an Arduino card, servo motors, power supply, LEDs and other, see Fig. 2) and materials to make models (ITEM aluminium profiles, PU foam foils, metallic network, glue, and free access to the lab materials).

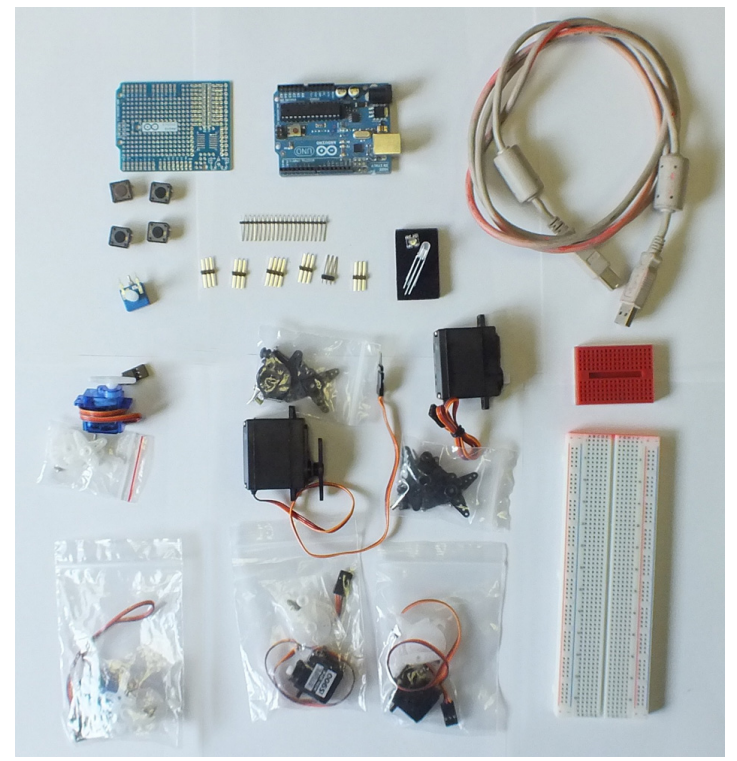

Fig. 2. Electronic components kit provided to each group.

\section{RESULTS}

The course was held so as to evaluate the format and the setting, in order to design an institutional course for the next academic year. The results are presented here from the points of view of both the teachers and the students.

\section{A. Feedback From Teachers}

This subsection reports teachers opinion of the degree to which the pedagogical goals of Section I were achieved.

Letting the groups self-organize to meet deadlines gave rise to different organization settings in different groups. In most, the design and the definition of both modeling and technical needs was developed by all the team members, in fullgroup discussions; they then divided the workload according to the competences of various members. Work was done autonomously, or in pairs, and frequent interactions within the group allowed members to check both the progress of the work and that they would meet the deadlines. In some groups, strong leadership emerged, but this was always a collaborative leadership, which is what is needed to help in driving the group to achieve a common goal. Italian schools give no specific training in leadership, so this experience was important for everybody involved; ideally, this should have been discussed at the end of the course, to highlight the mechanisms used in the various groups, but lack of time made this impossible. In any case, all the groups were able to be productive, exploiting the skills available in the group, including that of being able to get information and resources elsewhere.
Deadlines were treated as fluid by the tutors and managed according to situation. The authors were aware that it was a hard task to implement, in two days and from scratch, a robot showing four different emotions; they therefore sought to have all the groups at least implement a working prototype with some functionality. This was accomplished, with all the groups achieving working prototypes, three with one emotion implemented, and two with two, Figs 3 to 7. The first two exploited typical facial characteristics (i.e., eyebrows, lips, etc.) to render emotions. The remaining three were a fantasy object and two simple cubes: emotion was shown by lights generated by colored LEDs and transmitted through materials in different parts of the body, as well as by specific movements, such as vibrations, body shape changes, and opening of parts with given dynamics.

The checkpoint deadlines were too strict, particularly in the later phases of the activity, where more time was needed to implement shapes and movements. However, while more time was needed, and deadlines needed adjusting, the use of checkpoints was important to frame the work (everyone presenting their progress to the class at each checkpoint), and to flag any delays.

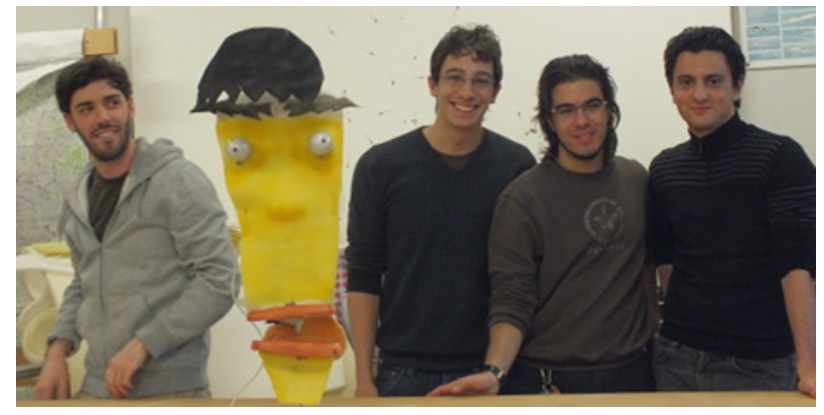

Fig. 3. A team with their final robot product: a "face"

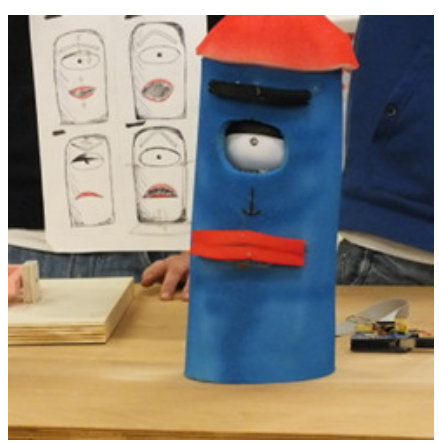

Fig. 4. Another of the final products (a "face"), together with the design of the emotional positions of mouth and eyebrow

Almost all the groups did well in defining problems without assistance. Each group discussed strategies to reach their goal, and most of them used sketches to represent emotional states and related expressions. In almost all groups designers took on the role of designing shape and movement, while engineers tried to achieve the desired behaviors. As mentioned below, some designers felt left out of the technical aspects by this way of managing the group. 


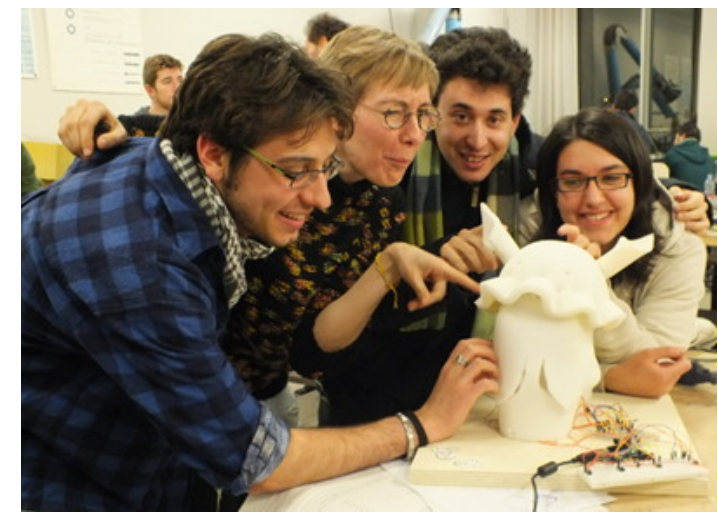

Fig. 5. A final, free-shaped robot designed by the only team including women

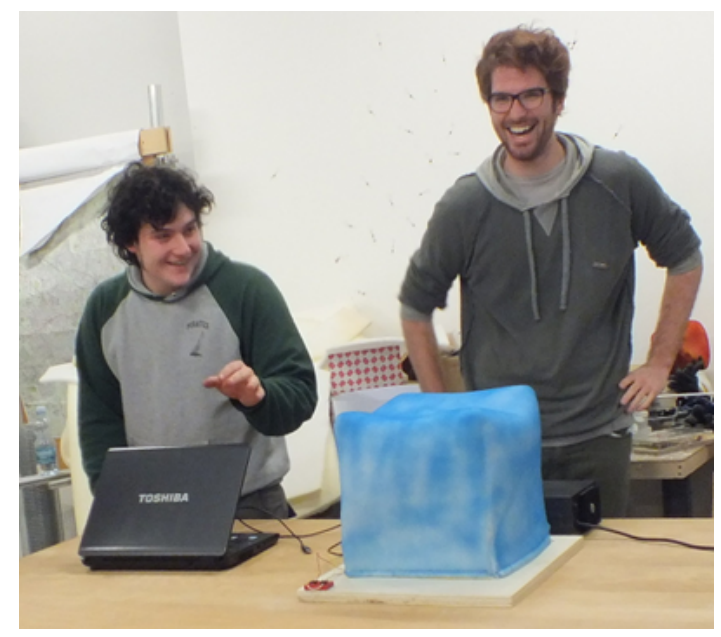

Fig. 6. A final cube robot able to change the shape of the body in various ways

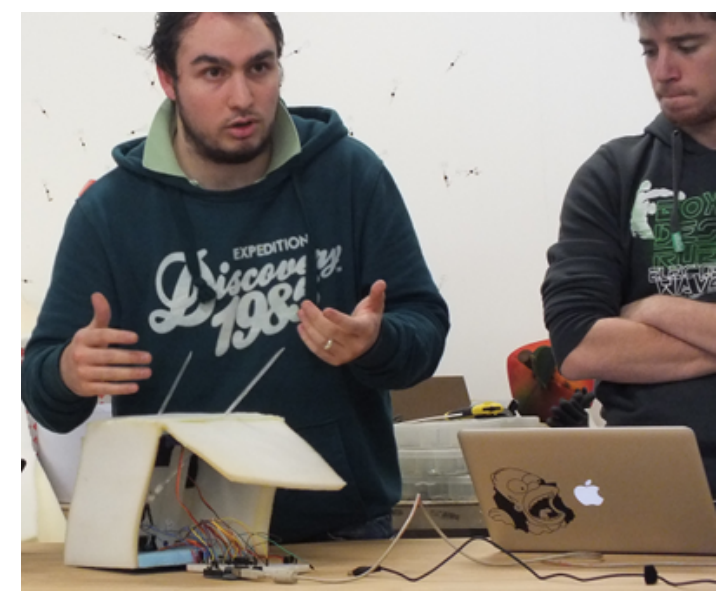

Fig. 7. The last of the final robot products: one of the two cubes, able to open parts of its body in various ways and with various dynamics, and to display colored lights in various parts of its body
Problem solving was also developed autonomously. Generally, students did not ask for help from the teaching staff, rather it was the staff who offered assistance. Students were absorbed in the task at hand. A correspondence can be noticed between an early definition of objectives, and a high-quality final robot: the more time dedicated to defining problems and discussing strategies, the worse the results were obtained. Time management was key for a successful result.

Some ingenuous mechanical solutions were proposed, mainly by the design students. This may be related to their usual design method, relying more on 3D-modeling software than on manual experimentation.

The students' presentation abilities were exercised at each checkpoint and in the final show. In some cases they were very effective, able to focus on important points and, in at least one case, to engage the audience. In almost all cases the (short) time limit given for presentations was met, and used to convey the expected information.

From the robotics concepts point of view, prototypes were running at the end of the course, showing that all the groups had been able to successfully face mechanical, electronics, and programming issues, to actually implement a robot. As expected, the theoretical content provided at the beginning was greatly complemented by the competence of the different group members, and the group activity, so that the learningby-doing and learning-by-interacting processes produced the final, desired result.

\section{B. Student Feedback}

At the end of the course the students were asked to answer a short paper questionnaire about the experience. Although it was late in the evening, and everybody was tired, each of them answered these eight items:

- Describe the three most positive aspects of the course.

- Describe the three most negative aspects of the course.

- Describe the timing for the following activities in your team: first and final ideas of emotion expression strategy, first and last mock-up, first and final firmware, first and final motor movement control.

- Describe the most significant difficulties encountered.

- Describe the funniest moment during the course.

- Suggest some advice for the students in the next course.

- Suggest some advice about the lunch break.

- Please, give any other suggestions.

Seventeen questionnaires were filled in (eight engineering students and nine design students, of whom two female students). Unfortunately, some of these only answered the items on the front of the page; they didn't realize that these continued on the other side. Two more students answered by e-mail: these answers are not considered in this analysis, since they were provided with different modalities from the others. All the answers were generally positive. Some students particularly appreciated the location (47\%), perhaps because in the Design School previous experiments in physical computing were performed in normal classrooms, and the Engineering School labs are not as well equipped as the one supporting this course. The friendly and collaborative mood was explicitly 
appreciated (29\%), as was the involvement of teachers and tutors throughout the duration of the course (18\%). A typical comment was: "As this course was taken on a voluntary basis and has no evaluation, we had fun taking it."

Some advice was given. Either more time should be allowed to achieve this kind of goals $(76 \%)$, or the complexity of the objectives should be reduced (5\%): "...three or five days would be better."

Some interesting differences were found between engineering and design students. All the engineering students declared their appreciation for the opportunity of working in interdisciplinary groups with engineers from different areas, and with designers. Only $44 \%$ of the design students have considered the interdisciplinary team as positive, one complaining about the (self-organized) division of tasks : "The computer engineer wrote all the code, so I could not learn anything about programming." $50 \%$ of the engineering students said that the Arduino platform was not suitable for the objectives (whereas in fact, using four servomotors at the same time could cause of power supply and control problems). $25 \%$ were happy to have encountered new materials for their prototypes.

For design students (44\%), advice for the next students was: "Study the basics of Arduino before the course." This underlines their sense of lacking the competence to be effective in their group.

From the comments, it is possible to deduce that, in interdisciplinary work, engineering students were looking for "new experiences", while design students were looking for "new knowledge". This sheds an interesting light on the structure of their respective tracks: engineering students probably suffer from a degree of monotony in their usual courses, an observation supported by other evidence not related to this specific experience, while design students would like to have the knowledge to be more active and autonomous in their work. This feedback has been reported to the respective Deans, and has been taken into consideration in designing the next course offering.

Some students suggested that a reading list should be provided before starting the course, to supply background knowledge, or suggested that there should be more structured guidelines during the course. Moreover, they suggested reducing the already short theoretical introduction, and starting directly with hands-on work. This assumes that the theoretical background is acquired in advance, and that this type of course is suitable for experimenting with a topic that is already known to some degree, if not mastered. Actually, although it was not required, some background knowledge was expected by the teachers, since the course goals were focused on achieving a specific result rather than on acquiring a completely new competence.

Other interesting comments include:

"Do it more often!", "Cool! I would take it again!" This seems to underline the lack of this type of experience, and the desire to have more of.

"Involve more girls (female students)." This comment might have been expected from a male student, especially from the area of engineering, where women are still relatively few (about 20\%); they were informed that design classes often have a higher rate of women. However, the comment was actually made by one of the female students. Moreover, a verbal comment by one of the female students was that robotics is not so appealing for females; she, too, preferred to work on technology applied to fashion. Although the gender issue is well known in teaching robotics, it can be addressed by presenting the activity properly (e.g., see the Roberta ${ }^{\circledR}$ project [10]); the world is full of enthusiastic girls and women working in robotics at all levels. The gender issue will be further addressed in the next offering of the course.

"Eating together in the lab was interesting, the best talks are during the breaks." This supports the idea of having "constructive breaks", where work stops, and students can exchange experiences informally.

The most exciting moment for most of the students (7\%) was "when the creature started to move!" Goal achieving is always exciting, but with robotics this gives a physical feedback of the work done, and is really rewarding. Learning robotics by building robots is much more interesting than by just studying it.

From these answers it emerges that all the participants enjoyed the course, which is important to validate what has been proposed. A critical aspect was certainly time, since two days are not enough to create a theoretical background, and then design, and implement a robot able to meet the goals proposed for this course.

\section{Discussion}

An interesting consideration concerns the platform used, Arduino. Most engineering students would have preferred to use a more specific platform (e.g., Pololu Mini Maestro). At the beginning, Arduino was selected because it appeared more user-friendly for designers, but during the course every team decided by themselves to consign the programming to engineers. In this situation, the engineers were working with a new and less powerful platform, and had to face limitations and problems. For this reason, the platform choice might have an important implication: the selection of Arduino enables interaction and knowledge sharing between designers and engineers, but seems to limit their technological potential. Easy access to the technical aspects is critical for courses, such as this, where the aim is not have students master a specific technology (as, e.g., in [11]), but to achieve higherlevel pedagogical goals, as is often done with younger students (as, e.g., in [12]). In multidisciplinary courses it is often clear that mastering the technology and mastering the topic (e.g., teaching in [13]) are achieved by different people. However, a certain level of understanding of technological issues is often desired also by non-technical people, as emerged also in [13].

In many situations, the groups had to face common, lowlevel problems (such as those related to Arduino) that were alleviated by inter-group communication, but that might also be reduced by providing libraries and support tools to enable a focus on higher-level problems and to allow a better exploitation of the available time, as mentioned also in [14]. This would help to focus efforts on conceptual aspects of the course, to which students from both Schools may be equally able to contribute. 
TABLE II

DIFFERENCES BETWEEN THE CRASH COURSE AND THE INSTITUTIONAL COURSE DESIGNED BASED ON THE FIRST EXPERIENCE

\begin{tabular}{|l|c||c|}
\hline & Crash Course & New Course \\
\hline Duration & 16 lab hours & 50 lab hours + homework \\
\hline Pre-lab self-trining & No & Yes \\
\hline Concept design & During Lab & Before Lab \\
\hline Checkpoints & Loose & Strict \\
\hline Final Presentation & Private & Public \\
\hline
\end{tabular}

\section{CONClusion}

The crash course presented here met most of the expectations, and provided, as desired, important information to be used in setting up a new course, to be offered the academic year 2012-2013. Table II lists aspects changed in the new course, based on the experience of the crash course.

The new course will be an institutional six-credits course. It will run for seven full days, for a total of fifty hours, plus homework. In a first day, in December, basic technical information will be provided, and homework, including selflearning of the needed technical aspects, will be set for all groups. This is intended to build a minimal background, so that students of both Schools can contribute to any phase of the prototype development. The students will work in groups to produce, first, the results of a brainstorming activity, to be presented as a document by January, so that a concept design will be ready at the beginning of the lab work. At the end of February, the groups will spend a whole, intensive week of work with the teachers in the lab. Each day will start with a checkpoint concerning the goals set at the beginning of the previous day. Then, some specific content related to the laboratory work to be done that day will be provided. Then, the laboratory work will start, each day with specific targets, with the final aim to of building a robot with given abilities. The strict organization of the activity over a longer period of time will increase the probability of obtaining working prototypes. The final presentation will be held in front of the general public on a day in the following week, and will be designed with professional criteria, themselves part of the teaching matter. The public will evaluate the aesthetic and functional aspects; these will be considered to making the final evaluation. This should encourage students to finish on time with a high quality prototype.

\section{ACKNOWLEDGMENT}

The authors would like to thank Giorgio Vignati from Physical Computing Laboratory, Matteo Piccoli and Matteo Dall'Amico from "Laboratorio di Modelli e Prototipi", and Fabrizio Rebagliatti from Macaia Studio, who taught the course, and all the the students who participated.

\section{REFERENCES}

[1] B. Gates, "A robot in every home," Scientific American Magazine, vol. 296, no. 1, pp. 58-65, 2007.

[2] D. A. Norman, The Design of Everyday Things. New York, NY: Basic Books, 2002.

[3] D. A. Goldberg, The Missing Basics and Other Philosophical Reflections for the Transformation of Engineering Education. New York, NY: Springer, pp. $145-158$.
[4] R. C. Schank, T. R. Berman, and K. A. Macpherson, Learning by doing. London, UK: Routledge, pp. 161-182.

[5] T. M. Duffy and D. J. Cunningham, Constructivism: Implications for the design and delivery of instruction. New York, NY: Simon and Schuster Macmillan, pp. 170-198.

[6] M. Banzi, Getting started with Arduino. Sebastopol, CA: MakeBooks, 2008.

[7] M. Mori, K. F. MacDorman, and T. Minato, "The uncanny valley," Energy, vol. 7, no. 4, pp. 33-35, 2005.

[8] T. Kanda, H. Ishiguro, T. Ono, M. Imai, and R. Nakatsu, "Development and evaluation of an interactive humanoid robot "robovie"," in Proceedings of IEEE International Conference on Robotics and Automation, vol. 2, 2002, pp. 1848-1855.

[9] R. Williams, The Animator's Survival Kit. London, UK: Faber\&Faber, 2002.

[10] A. Bredenfeld and T. Leimbach, "The Roberta ${ }^{\circledR}$ initiative," in Proceedings of SIMPAR 2010 - International Conference on Simulation, Modeling and Programming for Autonomous Robots, Darmstadt, D, pp. $558-567$.

[11] M. Krugman, "Teaching behavior based robotics through advanced robocamps," in Proceedings of 34th ASEE/IEEE Frontiers in Education Conference, Savannah, GA.

[12] A. F. Ribeiro and G. Lopes, "Summer on campus - learning robotics with fun," in Proceedings of 7th International Conference on Hands-on Science - HSci2010, Creta, GR, pp. 451-458.

[13] M. U. Bers and M. Portsmore, "Teaching partnerships: Early childhood and engineering students teaching math and science through robotics," Journal of Science Education and Technology, vol. 14, pp. 59-73, 2005.

[14] M. Bajracharya and E. Olson, "A low-cost, high-performance robotics platform for education and research," in Working Notes of AAAI Symposium on Robotics and Education.

Andrea Bonarini is a full professor at the Politecnico di Milano, Department of Electronics and Information. Coordinator of the AI and Robotics Lab since 1990, in 2012, he was nominated Fellow of the Alta Scuola Politecnica, a school for top students who wish to develop their potential in a multidisciplinary community. He is among the founders of the Italian Association for Artificial Intelligence (AI*IA) and of the Italian Chapter of the IEEE Computational Intelligence Society (Chair from 2008 to 2010). From 2003 to 2006 he was Coordinator of the Working Group on Robotics of the AI*IA. He has participated since 1997 in the Robocup initiative (member of the Executive Committee from 2002 to 2010). He has participated since 2001 in educational experiments involving robotics in elementary, secondary, high schools, and university. Since 1989, with his collaborators and students, he has built more than forty autonomous robots. His research interests include affective computing and autonomous robotic agents (in particular edutainment and robogames). He has published more than 140 peer-reviewed papers.

Maximiliano Romero was awarded a Master's degree in Industrial Design (1999), a Master's in Human Factors (2000), and a Ph.D. in Industrial Design and Multimedia Communication from Politecnico di Milano (2007). His research field and Ph.D. thesis focused on the role of industrial design for home automation and intelligent products. Contract professor of Physical Computing at Design School and operative coordinator of Physical Computing Lab at INDACO Department of the Politecnico di Milano, he has specialised in ergonomic research and development of ICT products, assistive technologies and products for disabled people. Since 2003, he has participated in research and product development in the health field, and has lectured in Italy, Argentina, Turkey, and Belgium. He is author of several patents and one of his products was selected for ADI design Index 2009 (index of best Italian design products). 